\title{
The Reflective Research on a New Space for Contemporary Jewelry Practice as a Form of Social Life
}

\author{
Xiaowen Liu \\ Xi'an University of Technology \\ Xi'an, China
}

\begin{abstract}
The application of talismanic elements in jewelry design has been an important part of jewelry design from time immemorial. With the vigorous development of modern jewelry industry and the continuous novation of modern jewelry design concepts. The charm, amulet or talisman design in contemporary jewelry has increasingly attention and is maturing, which is an effective form to promote contemporary jewelry engagement with histories, cultures and social life. This essay will adopt the methods of documentary, case study and observation to explore the meaning of amulets and its significance in contemporary jewelry.
\end{abstract}

Keywords—charm; amulet; talisman; contemporary jewelry; social life

\section{INTRODUCTION}

Contemporary jewelry is differentiated from other art forms such as sculpture and paining only by its scale (Anderson, 1998). The nature of jewelry is so caught up with social and psychological implications, that even the most insensitive of jewelers must have a dim awareness of how someone else will feel, and what the work's impact will be on another life. The design and fabrication of jewelry involves a transaction between the artist and somebody else as wearer. Joyaviva is an exhibition of 'live jewelry', which aspires to continue the story of contemporary. Each of the objects on display focuses on the function of charms, amulets or talismans and the witness that links people together, transforming private wishes into the shared stories.

\section{DeVelopment Process of Amulet Design}

Amulet, talisman, charm - these words are commonly used with something of the same significance, and for our purpose all three may be treated in common (Walsh, James, 1912). There is also another simple but authoritative explanation of amulet: protection against the unknown (Untracht, 1986). Amulets exist that are believed to have the power to repel the attack of an evil spirit. Some offer protection against natural disasters, endemic or epidemic diseases, poisoned bites or witchcraft, as well as security against myriad other threats to a healthy and happy existence.

\section{A. Ancient Amulet}

Jewels such as talismanic beads and objects of metal and other materials were believed to serve prophylactic or curative functions as well. Of extremely ancient usage, such objects held by a string or chain and worn against the skin any place on the body are commonly worn today in many parts of the world.

In the development of human culture, the idea evolved that the magic act of transformation itself imbued a condition of magic act of transformation itself imbued a condition of magic to the changed and perfected object. This belief was projected upon all early jewelry, whose prime purpose was for use as an amulet, a charm to protect the wearer against real or imagined calamities and threats to life. Belief in their effectiveness furnished humans with a psychological means of combating the hostility of both the real and the spirit-filled word in which they lived as in "Fig. 1" and "Fig. 2".

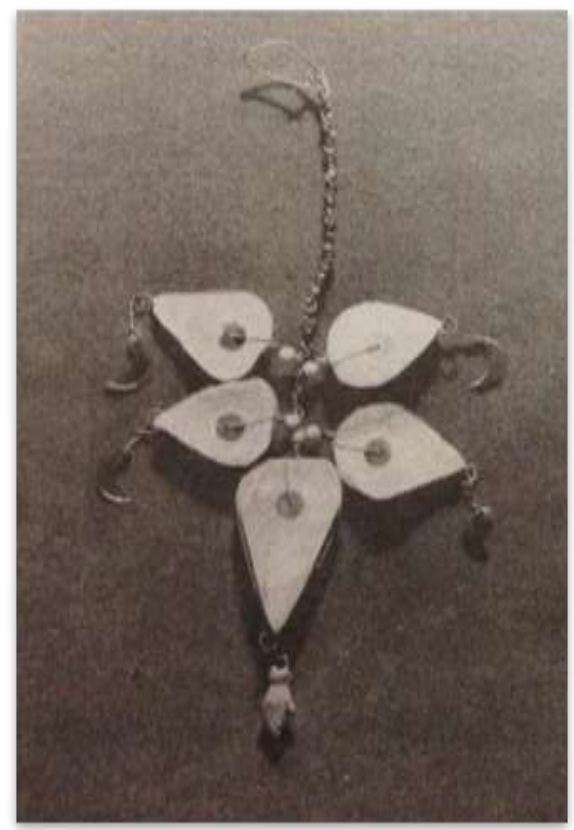

Fig. 1. Beirut, lebanon. Photo: Musee de I'Homme, Paris 
This is an amulet of five alum pieces held together by iron wire. Each part ends in a white metal lunar crescent, and the lowest in the hand of Fatima, both Muslim symbols of good luck, worn as protection against the evil eye. Max length $6 \mathrm{~cm}$; width $3 \mathrm{~cm}$.

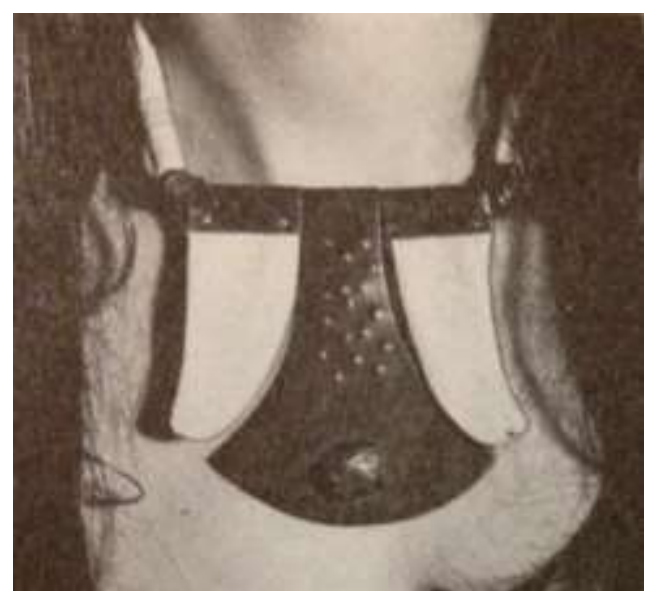

Fig. 2. Anita coudenhoye, Austria. Photo: Dolf Preisig.

This photograph shows an amulet in copper and ivory, with a stone. These pseudo amulets are examples of a return to magic primitivism.

\section{B. Modern Amulet}

Specific amulet forms developed because their shape and the ideas associated with it, or the material of which they were made were believed to be empowered with the ability to have an influence upon the prime concerns of humanslongevity, good health, wealth, sexual concerns, and luck or the favor of fate.

Jewelry has never been divorced from modern culture, even if it may be employed reflexively. According to Joyaviva, a modern amulet relates to "powerful object" that functions as witness that links people together, transforming private wishes into the shared stories. It also re-connects with its function in helping people navigate through their lives. The true power of objects such as charms, amulets and talismans is mot based in any supernatural forces. They enable us to share what are otherwise private hopes and fears. To give someone a charm is a social contract. When you receive it, you invite the giver to inquire later about your fortune.

For example, Charged Charm Cards (c3) in "Fig. 3" shown in this exhibition are credit card-sized sheets of sandblasted stainless steel from which pre-cut pendants and earrings can be punched out - and given away. The C3 artists Jill and Melissa noticed that the tradition of giving charms was often speculative; that lucky charms were often given for protection and future luck. But what if the bad thing had already happened? The artists set out to create a small kit of pieces, in the shape of a credit card, that could be used to create a piece of jewelry almost instantaneously that was always on-hand 'in case of an emergency'. As the c3 team explains, the c3s "are best put to use in emotionally charged situations that are big enough to elicit a sympathetic response, but not so big as might require a more somber gesture (Charged Charm Cards, Joyaviva, 2012)."

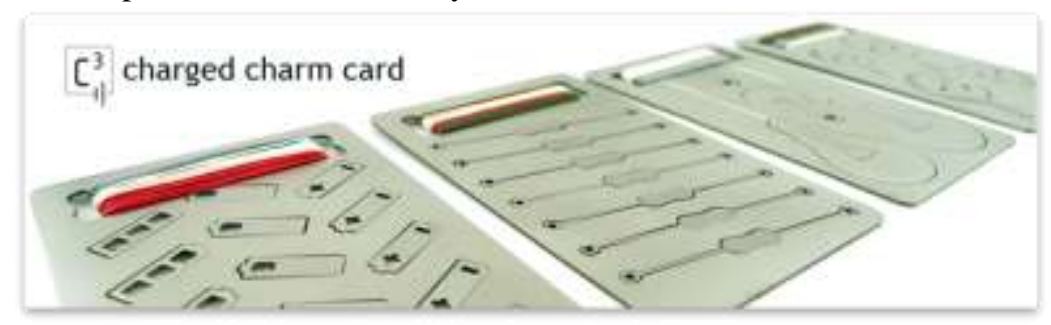

Fig. 3. Charged Charm Cards (c3) designed by Melissa Cameron \& Jill Hermans.

It functions as a catalyst for a change in an emotionally charged situation. The idea is to empower people by giving them the tools to enact quick emotional change on their friends, colleagues, and family. The donor detaches the charm, threads it with linen and administers it to the host. It is incorporated with incident report cards in "Fig. 4" and recipient report cards in "Fig. 5" to get feedback that how the charm made them feel, and their frequency of wear.

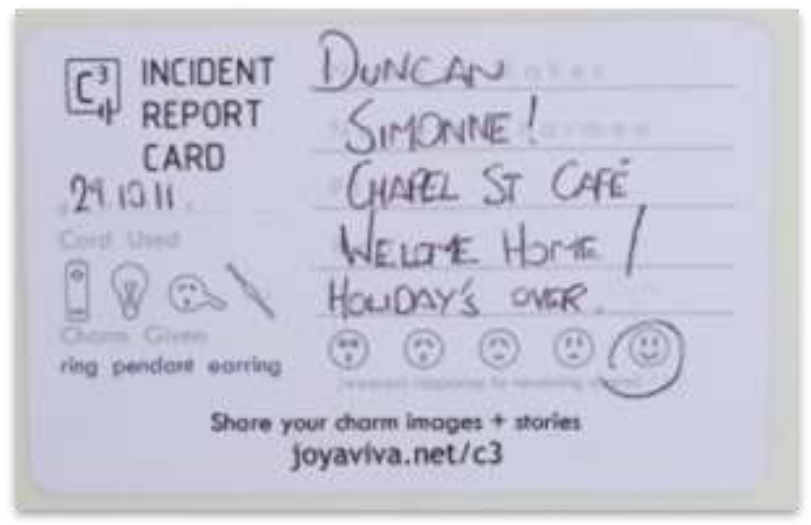

Fig. 4. Incident report cards. "Duncan's charming work helped a friend to resist the 'end of holiday blues'." 


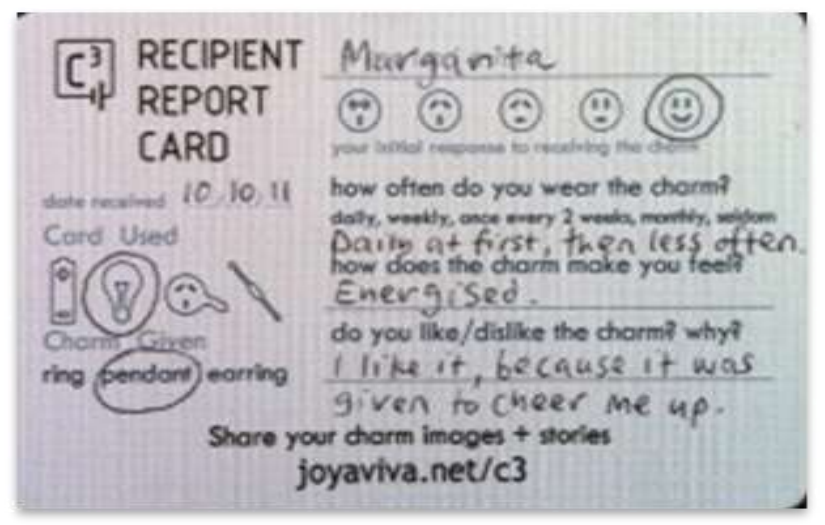

Fig. 5. Recipient report cards.

It is a piece of jewelry that is full of narratives and psychology not just about decoration. This psychology is not just between people but between people and objects. It is about how people change objects but it is also about how people and their emotions and actions are mediated and changed by their objects. The two designers Melissa and Jill explored the multivocal quality of the jewelry object and its capacity to acquire meaning and value through circulation amongst givers and wearers. Renewal of jewelry practice and identity could emerge from renewed engagement in the interaction between makers, wearers, audiences and jewelry objects (Cohn, 2009). Consequently, the Charged Charm Card provides us a broad and renewed vision of modern amulet and contemporary art jewelry-'live jewelry".

\section{SignifiCANCE OF AMULET}

\section{A. Mental and Behavior Effects}

There is a dimension to luck which goes beyond social convention. It is relatively uncontroversial to argue that belief can affect our performance (Joyaviva, 2012). Jewelry alters how a person is perceived: the wearer can employ the coded messages of different jewelry objects so she or he might appear radical, or conservative, or rich, or glamorous, young or old. Similarly, jewelry can alter how a wearer feels about him or herself as well as their performance. The psychology of adornment is not well understood, but it is obvious that outward image and inner image can be connected. For instance, the American jeweler Robert Lee Morris talks about a shy and nervous woman wearing a meaningful piece of jewelry: if she wears an object that is provided support from her families, friends or other group members, it will make her feel that she is the center of attention which attracts compliments, then she discovers a sense of confidence. This is not just speculation; he has actually seen it work for his clients (Thompson, 1989). Furthermore, previously, the placebo was a method of detecting error in medical research. Now scientists are taking the sugar pill seriously as a health measure. Even in the midst of disaster, such as an earthquake, there are inevitably stories of miraculous survival (Morton, Muller, Kevin Murray \& Whish, 2012). Thus, a charmed design for good fortune will increase our confidence in the future to some extent.

\section{B. Historical and Cultural Marker or Signifier}

Firstly, Amulet has great historical and cultural values. It reflects cultural identities and historical issues, and it also records the development of human civilization.

For instance, the photo below in "Fig. 6" is a boy wearing silver neck and arm amulets. When hollow, these contain written paper prayers or incantations. It is worn by children all over India in belief that they protect them from various evils that may befall them before adulthood. Some potent charm pendant types are made of tiger's claws (Untracht, 1986). Hence, this silver amulet is a symbol of traditional Indian culture, which recorded the India traditional metal folk customs and legends.

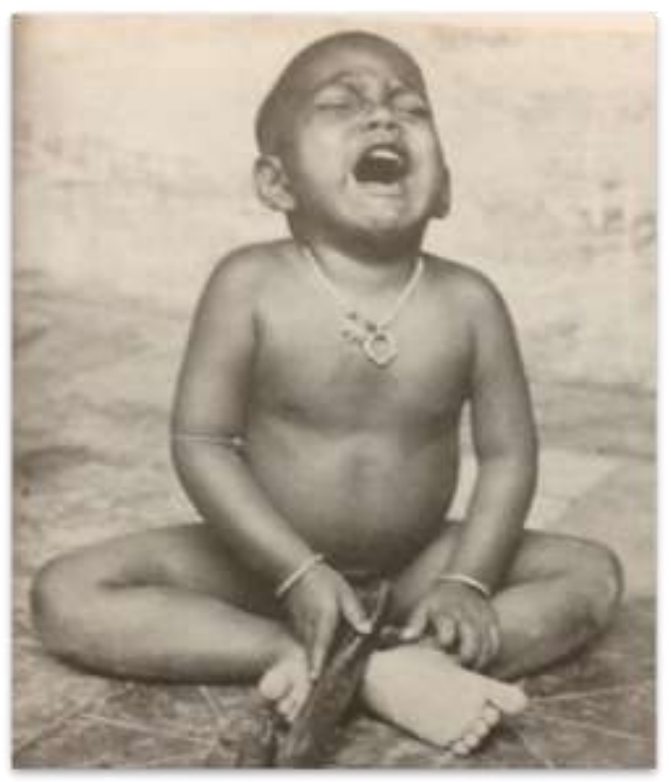

Fig. 6. Banaras, Uttar Predesh. Photo: Oppi

The jewelry works "For the battle of Monkey, Rat and Dragon in "Fig. 7", which is designed by Jin ah Jo shown in Joyaviva, is evidence. It produced a series of charms based on Korean mudang, which consist of red symbols on yellow paper; they include Chinese characters for luck, fortune, longevity and fertility - called Chinese zodiac sign in "Fig. 8" (Jin ah Jo, Joyaviva, 2012). The Chinese calendar of astrology is a twelve-year, cyclical, calendar represented by twelve animals. Yin-Yang, the elements and the animal a person represents are all present at the time of birth and present limitations on them. This is not necessarily a negative occurrence. In Chinese astrology a person's fate is not predetermined at birth. It is believed that individuals have the capacity to direct the course of their own lives and determine their own successes. Chinese calendar astrology provides the individual with the tools to make certain this happens (The Chinese Calendar of Astrology, 2009). 


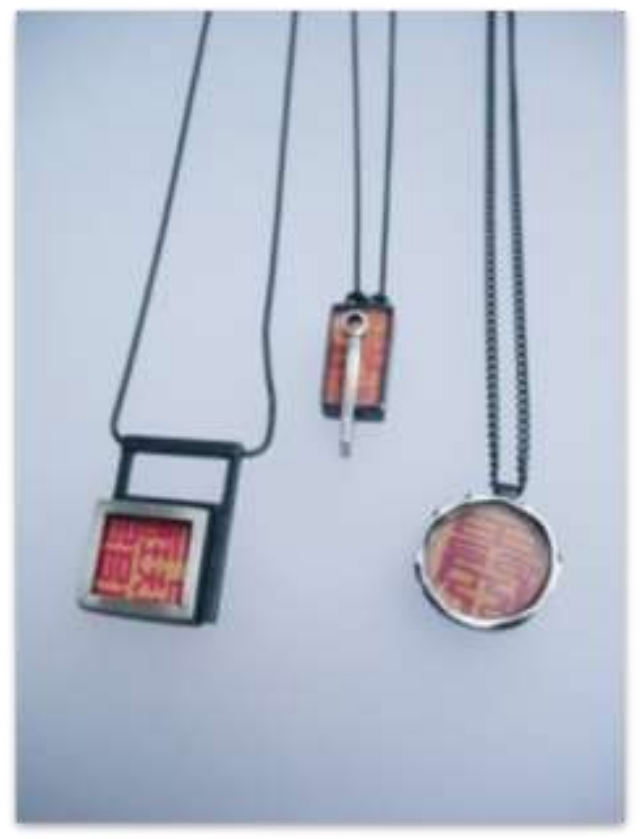

Fig. 7. For the battle of Monkey, Rat and Dragon

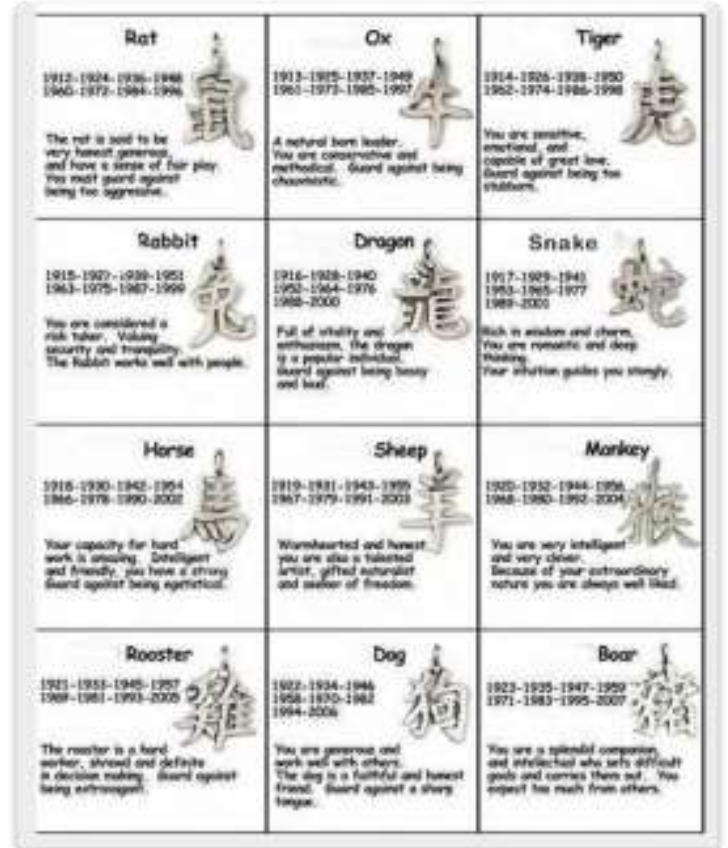

Fig. 8. Chinese zodiac sign.

Therefore, amulet is important cultural heritage that can reflect historical and cultural narratives, ensure the continuity of history and revitalize the historical background of a country that may date back hundreds of years, in the process enhancing its charm. The amulet's role as a marker or signifier is rather complex when tested by heterogeneous and multicultural societies. This construction between object and social psychology appears to work well between humans of a shared culture, with the object as bridge. It is part of cultural understanding and place rendering and organizing the interplays from reality (Findeis, 2006).

\section{Narratives Expression}

Furthermore, the jewelers in Joyaviva are particularly focused on the role of the object in building relations between people. Luck is a useful commodity for social relations. It is the things we cannot control that define our common humanity. Without them, we would have no stories to share. Everything would run like clockwork.

The maker's own history shared with all its richness imbedded in socio-historical experience is hugely important and cannot be separated from the whole and will have a place in the object-work no matter how subtle. The one thing amulets can do well is to upload narratives, communicating meaning. The uploading of a personal story can abruptly and unintentional overlay the maker's meaning. "For the battle of Monkey, Rat and Dragon" is also a good example to explain this. As mentioned before, it is created by Jin ah Jo. She was born in Korea, and gained her first formal training in jewelry at the Korea Gemmology institute in 1997-98. She moved to Australia and in 2000 studied art and design at Box Hill TAFE. She was so excited and happy to place herself in the new environment but at the same time she experienced three big miserable happenings in her life, which involves her valuables including passport being stolen, her place being burgled and herself being mugged on the street in the middle of night on the way to go home. She said: "Thinking about almost 12 years ago, year 2000, according to my Chinese Zodiac sign I was astrologically caught in three years of misfortune. Especially the year 2000 was the first year for me to come to Australia and the last year of three years of misfortune. 12 years later, this year 2001 is the initial year of another circle of three years of misfortune for my Zodiac sign, rat along with monkey and dragon ( Jin ah Jo, 2012)." So I decided to make a project to be the real lucky charm for the wearers for the next three years." These are the design issues, historical and cultural narratives embodied in this jewelry work. Such jewelry promises to be a good 'uploader' of the personal story, which might be different from the "political in your face" exclamation. It enables us to share what are otherwise private hopes and fears. However, this design also has limitations because this kind of share is based on common culture and common faith as Chinese zodiac sign is common and popular in some Asian countries like China, Korea and Japan.

\section{CONCLUSION}

In conclusion, this essay developed a deep historical and cultural research and critical evaluation of works by contemporary jewelers and their engagement with the theme in a contemporary context.

The charm, amulet or talisman is an effective form to help contemporary jewelry engage with histories, cultures and social life. By distinguishing the values of jewelry in terms of its economic, political, social and sentimental value, we are missing something vital. The traditional explanation of jewelry is not sufficient to explain the character of 
contemporary art jewelry. Contemporary 'art jewelry' has gone far away from the initial function of jewelry to adorn, distinguish and decorate. 'Author jewelry', which is a fairly good word to describe the character of contemporary art jewelry, is detached from life. No matter how hard jewelry makers try to make links to connections to everyday life.

\section{REFERENCES}

[1] Anderson, P 1998, Contemporary jewelry in Australia and New Zealand, Craftsman House and G+B Arts International, Toppan, Singapore.

[2] Walsh, James, J 1912, Amulets, Talismans, Charms, PsycBooks

[3] Untracht, O 1986, Jewelry Concepts and Technology, Doubleday \& Company, INC., Garden City, New York

[4] Cemeron, M, Hermans J 2012, Charged Charm Cards, Joyaviva, viewed 22 September 2012 < http://www.joyaviva.net/c3/samplepage>

[5] Cohn, S 2009, Recording Jewelry: Identity, Body, Survival, unpublished Ph.D. thesis, COFA, University of NSW

[6] Joyaviva 2012, Live Jewelry across the Pacific, UTS. Gallery

[7] Thompson, B 1989, Jewelry Australia Now, Craft Australia series publication, Crafts Council of Australia, Sydney, NSW, 2000

[8] Morton, T, Dr Muller, L, Murray, K, Whish, A 2012, Luck without Magic, UTS. Gallery

[9] Jin Ah Jo 2012, For the battle of Monkey, Rat and Dragon, Joyaviva, viewed 22 September 2012 < http://www.joyaviva.net/c3/samplepage>

[10] The Chinese Calendar of Astrology, Divine Answers, 2009, view 22 September 2012,<http://www.divineanswers.com/chinese-calenderastrology/>

[11] Findeis, K 2006, On Location - Making Stories: Siting, Citing, Sighting, Jewelers and Metalsmiths Group of Australia, NSW Inc. in conjunction

[12] Jin ah Jo 2012, Jin ah Jo about her work, Joyaviva, UTS. Gallery. 